\title{
The Environmental Neurotoxicant PCB 95 Promotes Synaptogenesis via Ryanodine Receptor-Dependent miR132 Upregulation
}

\author{
Adam Lesiak, ${ }^{1}$ Mingyan Zhu, ${ }^{1}$ Hao Chen, ${ }^{2}$ Suzanne M. Appleyard, ${ }^{1}$ Soren Impey, ${ }^{3}$ Pamela J. Lein, ${ }^{2}$ and Gary A. Wayman ${ }^{1}$ \\ ${ }^{1}$ Integrative Physiology and Neuroscience, Washington State University, Pullman, Washington 99164, ${ }^{2}$ Department of Molecular Biosciences, University of \\ California, Davis, California 95616, and ${ }^{3}$ Oregon Stem Cell Center, Oregon Health and Science University, Portland, Oregon 97239
}

\begin{abstract}
Non- dioxin-like (NDL) polychlorinated biphenyls (PCBs) are widespread environmental contaminants linked to neuropsychological dysfunction in children. NDL PCBs increase spontaneous $\mathrm{Ca}^{2+}$ oscillations in neurons by stabilizing ryanodine receptor (RyR) calcium release channels in the open configuration, which results in CREB-dependent dendritic outgrowth. In this study, we address the question of whether activation of CREB by NDL PCBs also triggers dendritic spine formation. Nanomolar concentrations of PCB 95, a NDL congener with potent RyR activity, significantly increased spine density and the frequency of miniature EPSCs in primary dissociated rat hippocampal cultures coincident with upregulation of miR132. Inhibition of RyR, CREB, or miR132 as well as expression of a mutant p250GAP cDNA construct that is not suppressed by miR132 blocked PCB 95 effects on spines and miniature EPSCs. PCB 95 also induced spine formation via RyR-and miR132-dependent mechanisms in hippocampal slice cultures. These data demonstrate a novel mechanism of PCB developmental neurotoxicity whereby RyR sensitization modulates spine formation and synaptogenesis via CREB-mediated miR132 upregulation, which in turn suppresses the translation of p250GAP, a negative regulator of synaptogenesis. In light of recent evidence implicating miR132 dysregulation in Rett syndrome and schizophrenia, these findings identify NDL PCBs as potential environmental risk factors for neurodevelopmental disorders.
\end{abstract}

Key words: CREB; dendritic spines; developmental neurotoxicity; microRNA; polychlorinated biphenyls; synaptogenesis

\section{Introduction}

Dendritic spines are the primary site of excitatory synaptic input, and their formation is critical for normal neural function (Segal, 2005). Abnormalities in the density or shape of dendritic spines are associated with many neurodevelopmental disorders, including mental retardation, autism spectrum disorders (ASDs), and schizophrenia (Fukuda et al., 2005; Penzes et al., 2008; Bourgeron, 2009; Garey, 2010; Svitkina et al., 2010). Dendritic spines are exquisitely responsive to external cues, especially during development. The effects of external cues on spine morphology are mediated primarily by calcium-dependent signaling pathways (Cline, 2001; Saneyoshi et al., 2010), and we have recently demonstrated that calcium-dependent signaling pathways are vulnerable to modulation by polychlorinated biphenyls (PCBs) (Wayman et al., 2012a).

PCBs are a class of synthetic organic compounds grouped according to their molecular structure as dioxin-like or non-

Received July 6, 2013; revised Nov. 19, 2013; accepted Nov. 23, 2013.

Author contributions: A.L., H.C., S.M.A., P.J.L., and G.A.W. designed research; A.L., M.Z., H.C., and S.I. performed research; A.L., M.Z., H.C., S.M.A., P.J.L., and G.A.W. analyzed data; A.L. and P.J.L. wrote the paper.

This work was supported by the National Institutes of Health (R01 ES014901, R01 ES017425, P42 ES04699, R01 MH086032, P01 ES011269, and T32 ES007059), the United States Environmental Protection Agency (R833292 and R829388), the Hope for Depression Research Foundation, and the J.B. Johnson Foundation.

The authors declare no competing financial interests.

Correspondence should be addressed to Dr. Pamela J. Lein, University of California, Davis, Department of Molecular Biosciences, 1089 Veterinary Medicine Drive, Davis, CA 95616. E-mail: pjlein@ucdavis.edu.

DOI:10.1523/JNEUROSCI.2884-13.2014

Copyright $\odot 2014$ the authors $\quad 0270-6474 / 14 / 340717-09 \$ 15.00 / 0$ dioxin-like (NDL) (Safe, 1994). Although commercial production of PCBs was banned in most countries, including the United States in the 1970s, NDL PCBs persist in environmental samples (Kostyniak et al., 2005; Hwang et al., 2006) and human tissues (Stewart et al., 1999; DeCaprio et al., 2005). Epidemiological studies have demonstrated a negative association between developmental exposure to environmental PCBs and measures of neuropsychological function in infancy or childhood (Seegal, 1996; Schantz et al., 2003; Carpenter, 2006; Korrick and Sagiv, 2008; Winneke, 2011). We previously reported that Aroclor 1254 (A1254), a commercial PCB mixture rich in NDL PCBs, interferes with dendritic growth in weanling rats coincident with behavioral deficits (Yang et al., 2009). More recently, we demonstrated that the NDL congener PCB 95 stimulates dendritic outgrowth in vivo and in vitro (Wayman et al., 2012a, b). Nanomolar concentrations of PCB 95 stabilize ryanodine receptors (RyRs) in the open configuration, increasing $\mathrm{Ca}^{2+}$ release from intracellular stores (Pessah et al., 2010). In cultured hippocampal neurons, PCB 95 sensitization of RyRs increases $\mathrm{Ca}^{2+}$ oscillations, and this triggers sequential activation of CaM kinase, Mek/ERK, CREB, and Wnt to enhance dendritic growth (Wayman et al., 2012a). CREB activation also mediates activity-induced dendritic spine formation in cultured hippocampal neurons via upregulation of miR132, which suppresses the translation of p250GAP, a negative regulator of synaptogenesis (Impey et al., 2010). Here, we report that that RyR sensitization by PCB 95 activates this same CREB- 
dependent signaling pathway to trigger dendritic spine formation and synaptogenesis.

\section{Materials and Methods}

Materials. PCB 95 (2,2',3,5',6-pentachlorobiphenyl, >95\% purity) was purchased from AccuStandard. FLA365 was a generous gift from Isaac Pessah (University of California, Davis, California). Construction and characterization of the following expression vectors were previously published: siRNA specific for RYR1 or RYR2 (Wayman et al., 2012b), mRFPtagged $\beta$-actin (Impey et al., 2010), anti-miR132 (Wayman et al., 2008), ACREB (Arthur et al., 2004), shCREB (Wayman et al., 2006), constitutively active (ca) CREB (Cardinaux et al., 2000), tomato florescent protein (TFP) (Impey et al., 2010), and wild-type (WT) and mutant (MT) p250GAP (Wayman et al., 2008).

Cell culture. Cells were dissociated from hippocampi of postnatal day 1-2 (P1-P2) Sprague-Dawley rats of both sexes (Charles River Laboratories), plated at a density of $3.4 \times 10^{8}$ cells per $\mathrm{cm}^{2}$ on glass coverslips precoated with poly-L-lysine (Sigma; molecular weight 300,000) and maintained in Neurobasal A medium (Invitrogen) supplemented with B27 (Invitrogen) as described previously (Brewer, 1997). Organotypic hippocampal slices from P5 Sprague-Dawley rats (Charles River Laboratories) were cultured for $3 \mathrm{~d}$, as described previously (Barria and Malinow, 2002).

Transfection. Dissociated hippocampal neurons were transfected on DIV6 using LipofectAMINE 2000 (Invitrogen) according to the manufacturer's protocol. Alternatively, dissociated hippocampal neurons were transfected by electroporation before plating using the Amaxa Nucleofector kit (Lonza Bioresearch) according to the manufacturer's instructions. Hippocampal slice cultures were transfected with pCAG-TFP \pm various plasmids using a Helios Gene Gun (BioRad) as previously described (Barria and Malinow, 2002).

Dendritic spine imaging and quantification. Cultures were fixed with 4\% paraformaldehyde in $60 \mathrm{~mm}$ PIPES, 25 mм HEPES, 5 mm EGTA, 1 $\mathrm{mm} \mathrm{MgCl}_{2}, 87.6 \mathrm{~mm}$ sucrose, $\mathrm{pH}$ 7.4, for $20 \mathrm{~min}$ at room temperature. Fluorescent images were obtained using Slidebook 4.2 Digital Microscopy Software interfaced to an Olympus IX81 inverted confocal microscope (Olympus Optical) with a $60 \times$ oil-immersion lens, numerical aperture 1.4, and resolution $0.280 \mu \mathrm{m}$. Dendritic spine density was measured on primary and secondary dendrites at a distance of at least $150 \mu \mathrm{m}$ from the soma. Two to three segments of the dendritic arbor from at least 24 neurons were analyzed for each data point reported. Each experiment was repeated at least twice (three times or more for most conditions) using cultures prepared from independent dissections. Dendrite length was determined using ImageJ 1.41 (National Institutes of Health, Bethesda, MD) and the neurite tracing program Neuron J. Spines were manually counted and classified by an individual blinded to experimental condition. Spines were categorized using slightly modified criteria as previously described (Harris et al., 1992): (1) mushroom: dendritic protrusion with a distinct actin rich head greater than the diameter of the shaft (thin spines as defined by criteria described previously) (Harris et al., 1992) were included in this category; (2) stubby: actin rich protrusion with a head size similar to the total length of the spine and no discernible shaft; and (3) filopodia: dendritic protrusion without a discernible actin rich spine head. Total spines were the combined total of mushroom and stubby spine types.

$R N A$ isolation, reverse transcription, and $q P C R$. RNA was isolated using Trizol (Invitrogen) according to the manufacturer's protocol. Contaminating DNA was eliminated using the Turbo DNA-free kit (Applied Biosystems). RNA concentration was determined using a Nanodrop Spectrophotometer (ThermoScientific). Total RNA (100 ng) was reverse transcribed using Superscript III First Strand Synthesis kit with random hexamers according to manufacturer protocols, including no RT controls (Invitrogen). qPCR was performed using Bio-Rad IQ5 qPCR thermocycler with the platinum qPCR supermix (Invitrogen) according to manufacturer protocols, with SYBR Green (Invitrogen) and Fluorescein (Bio-Rad) diluted to $1 \times$ final concentration. Primers and cycling conditions for pre-miR132 were CCGCGTCTCCAGGGCAAC and CCTCCGGTTCCCACAGTAACAA cycled at $2 \mathrm{~min}$ at $50^{\circ} \mathrm{C}, 2 \mathrm{~min}$ at $95^{\circ} \mathrm{C}$, then 45 cycles of $15 \mathrm{~s}$ at $95^{\circ} \mathrm{C}$ and $45 \mathrm{~s}$ at $68^{\circ} \mathrm{C}$. The housekeeping gene hypoxanthine-guanine phosphoribosyltransferase (HPRT) cycling and primer sequences were as described previously (Santos and Duarte, 2008). Relative starting quantity was calculated using a standard curve $2 \times$ dilution series, and pre-miR132 relative starting quantity was normalized to HPRT.

Immunocytochemistry. Cultures were fixed and reacted with antibody specific for synapsin-1 (Synaptic Systems) as previously described (Impey et al., 2010). The percentage colocalization of RFP- $\beta$-actin-positive dendritic spine heads with presynaptic markers was determined from 50 to 100 spines on 6 different neurons per treatment group.

Western blotting. Lysates from dissociated hippocampal neurons were separated by electrophoresis, blotted, and probed for p250GAP and the loading control ERK1/2 (Santa Cruz Biotechnology) as previously described (Nakazawa et al., 2003), using anti-Rb IR700 and anti-Ms IR800 as secondary antibodies (Rockland). Blots were imaged using a LICOR Odyssey scanner (Li-COR).

Whole-cell recordings, miniature EPSC ( $m E P S C$ ) analysis. Patch-clamp experiments were performed on cultured hippocampal neurons transfected with mRFP- $\beta$-actin and test plasmids as described previously (Benoist et al., 2011; Lesiak et al., 2013).

Statistical analyses. Data are presented as the mean \pm SEM. Significant differences were determined using one-way ANOVA $(p<0.05)$ followed by Tukey's post hoc test and Student's $t$ test using Prism software.

\section{Results}

\section{PCB 95 stimulates synaptogenesis}

Dendritic spines of individual pyramidal neurons in high-density hippocampal neuron-glia cocultures were visualized by expressing an mRFP- $\beta$-actin cDNA construct that selectively labels spines but does not alter intrinsic dendritic spine density or spine size relative to sister cultures expressing tomato red fluorescence (Saneyoshi et al., 2008). Exposure of dissociated hippocampal neurons from DIV7-DIV12 to PCB 95 at $200 \mathrm{nM}$, a concentration previously shown to enhance dendritic outgrowth (Wayman et al., 2012b), significantly increases the density of dendritic spines to $\sim 50 \%$ above that observed in vehicle control cultures (Fig. $1 A$ ). Dendritic spines can be categorized as either mushroomshaped, which are mature fairly stable synaptic connections, or stubby, which are more immature less stable synaptic connections. The increase in total dendritic spine density observed in PCB 95-treated cultures reflects an increase in both mushroomshaped and stubby spine types; in contrast, PCB 95 has no effect on the density of filopodia projections (total spines $p=0.0001$, mushroom $p=0.0009$, stubby $p=0.0004$, filopodia $p=0.5060$ as determined by Student's $t$ test). To determine whether the morphological changes in dendritic spine density represent a change in synaptic connectivity, hippocampal cultures were immunostained for the presynaptic marker synapsin-1. Synapsin-1 immunoreactivity is juxtapositioned within $0.5 \mu \mathrm{m}$ of $\mathrm{mRFP}^{+}$ dendritic spine heads in $\sim 90 \%$ of dendritic spines examined in both control and PCB 95-treated neurons (Mann-Whitney, $p=$ 0.1320; Fig. $1 F, G$ ). Additional studies confirmed colocalization of $\mathrm{mRFP}^{+}$spine heads with immunoreactivity for the postsynaptic marker PSD 95 (data not shown). Because the frequency of mEPSCs directly correlates with the density of functional dendritic spines (Murase et al., 2002), we also measured mEPSCs. Electrophysiological recordings indicated that PCB 95 significantly increases mEPSC frequency (Fig. $1 B, C$ ). In contrast, the amplitude and decay time of mEPSCs are not altered by exposure to PCB 95 (one-way ANOVA, $F_{(1,58)}$, Freq $F=31.534, p<0.001$, $\operatorname{Amp} F=0.565, p=0.455$, DT $F=2.341, p=0.131$; Tukey's post hoc; Fig. $1 D, E)$. 
A

\section{Control}

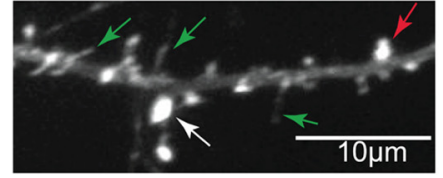

\section{РCB 95}

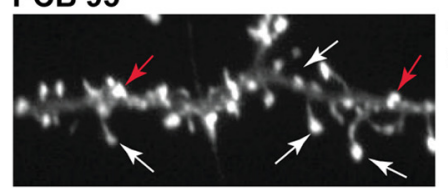

B

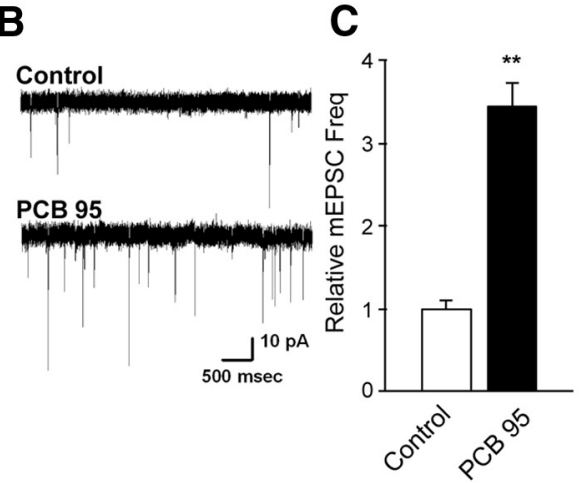

$\mathbf{F}$

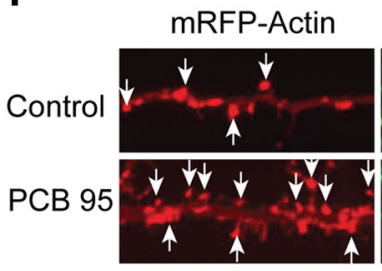

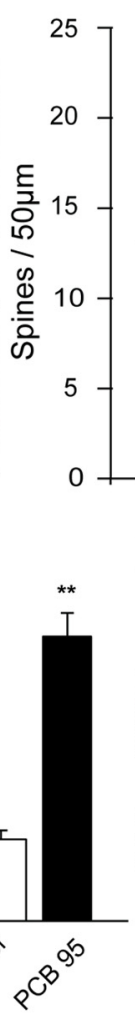

.

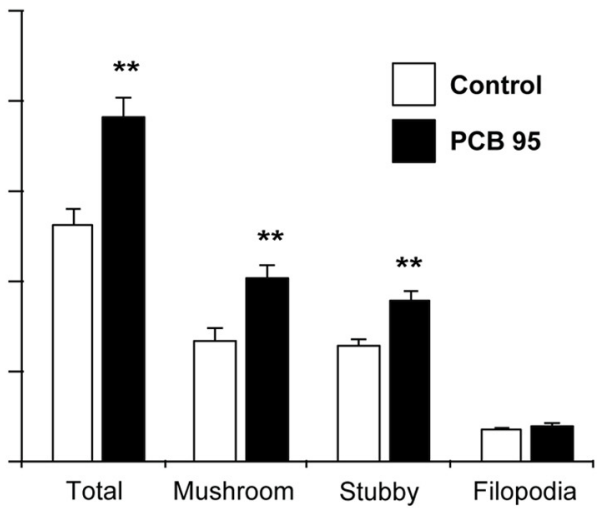

D

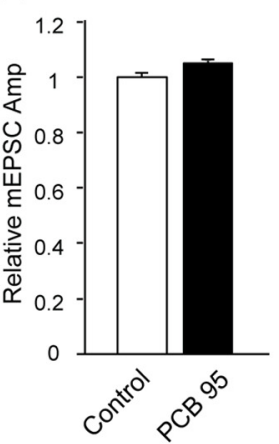

$\mathbf{E}$

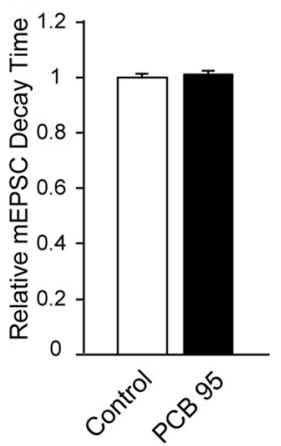

G

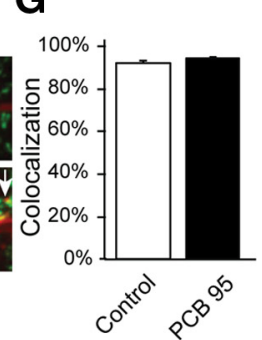

Figure 1. $\quad P C B 95$ stimulates synapse formation. DIV6 dissociated hippocampal neurons transfected with mRFP-tagged $\beta$-actin were treated with vehicle or PCB 95 (200 nm) from DIV7-DIV12.A, Representative photomicrographs of mRFP ${ }^{+}$cells and quantification of dendritic spines and filopodia ( $n=23-24$ neurons). White arrows point to mushroom-shaped spines; red arrows, stubby spines; green arrows, filopodia. $\boldsymbol{B}$, Representative traces of mEPSCs from control and PCB 95-treated cultures. C-E, Quantitative analyses ( $n=38-32$ neurons) demonstrating PCB-induced fold change in mEPSC frequency $(\boldsymbol{C})$, amplitude $(\boldsymbol{D})$, and decay time $(\boldsymbol{E})$ relative to control neurons. $\boldsymbol{F}$, Representative photomicrographs of RFP ${ }^{+}$cells immunostained for the presynaptic marker synapsin-1. G, Percentage of RFP ${ }^{+}$spines juxtapositioned within $0.5 \mu \mathrm{m}$ of a synapsin-1-immunoreactive puncta $(n=6$ neurons, $50-100$ spines per neuron). ${ }^{*}$ Significantly different from control at $p<0.001$ (Student's $t$ test, $\boldsymbol{A}$; one-way ANOVA, $(-\boldsymbol{E}$ ).

PCB 95-induced synaptogenesis requires RyR activity

PCB 95 is a potent RyR sensitizer, and this interaction alters intracellular $\mathrm{Ca}^{2+}$ levels (Pessah et al., 2010). To determine whether PCB 95-induced synaptogenesis is mediated by effects on RyR activity, dissociated hippocampal cells were exposed to PCB 95 in the presence of the RyR channel blocker FLA365 (Chiesi et al., 1988; Mack et al., 1992). FLA365 has no effect on dendritic spine density in vehicle control cultures but significantly inhibits PCB 95-induced increases in total, mushroom, and stubby spine density (ANOVA: $F_{(7,183)}$, total $F=16.45, p<0.0001$, mushroom $F=15.80, p<0.0001$, stubby $F=12.05, p<0.0001$, filopodia $F=1.955, p=0.0635$, Tukey's post hoc; Fig. 2A). RyR1 and RyR2, but not RyR3, are expressed in this hippocampal cell culture model (Wayman et al., 2012b), and expression of siRNA specific for either RyR1 or RyR2 (Wayman et al., 2012b) suppresses PCB 95 effects on dendritic spine density but does not alter basal dendritic spine density (Fig. 2A). No significant treatment-related differences in the percentage of $\mathrm{RFP}^{+}$spines juxtapositioned to synapsin-1 immunoreactivity were observed (data not shown). Consistent with these findings, FLA365 treatment or expression of siRyR1 or siRyR2 inhibits PCB 95induced increases in mEPSC frequency but has no effect on mEPSCs in control cultures (ANOVA: FLA series $F_{(3,51)}$; Freq $F=15.92$, $p<0.0001, \operatorname{Amp} F=8.722, p<0.0001$, DT $F=0.5313, p=0.6629$; ANOVA: siRYR series $F_{(5,87)}$; Freq $F=9.138, p<0.001$, Amp $F=2.311, p=0.051$, DT $F=1.376$, $p=0.241$; Tukey's post hoc; Figure $2 B-D$ ) (all constructs were tested on multiple cultures, with each normalized to an average of their own controls).

\section{PCB 95-induced synaptogenesis requires CREB-miR132- p250GAP signaling}

We previously demonstrated that activitydependent synaptogenesis is mediated by sequential CREB activation, miR132 upregulation, and repression of p250GAP translation (Fig. 3A) (Impey et al., 2010). Loss-of-function and gain-of-function approaches were used to interrogate the role of CREB in PCB 95-induced synaptogenesis. Expression of a dominant interfering mutant (MT) of CREB, ACREB (Arthur et al., 2004), has no effect on spine density in control cultures but significantly inhibits PCB 95-induced increases in total, mushroom, and stubby spine density (ANOVA: $F_{(6,161)}$; total $F=56.09$, $p<0.0001$, mushroom $F=50.10, p<$ 0.0001 , stubby $F=37.87, p<0.0001$, filopodia $F=8.061, p<0.0001$, Tukey's post hoc; Fig. 3B). Similarly, knockdown of CREB expression by shCREB (Wayman et al., 2006) reduces the density of all spine types below control levels in the absence or presence of PCB 95 (Fig. 3B). Conversely, transfection with constitutively active (ca) CREB (Cardinaux et al., 2000) phenocopies the effects of PCB 95 on mature mushroomshaped spines but did not increase immature stubby spine density (Fig. 3B). No significant differences in the percentage of RFP ${ }^{+}$ spines in close physical apposition to synapsin-1 immunoreactivity were observed across treatments (data not shown).

To interrogate the role of miR132 in PCB 95-induced synaptogenesis, we first quantified the expression of pre-miR132 transcript in lysates from hippocampal cultures treated with PCB 95 (200 nM) or vehicle for 2 h. PCB 95 causes a threefold increase in the premiR132 transcript (Fig. 4A), which is decreased in cultures electroporated with ACREB to inhibit CREB-dependent transcription (ANOVA: $F_{(3,82)}=13.94, p<0.0001$, Tukey's post hoc; Fig. $4 A$ ). Transfection with a $2^{\prime} O$-methyl RNA oligonucleotide that targets miR132 (anti-miR132) (Impey et al., 2010) blocks PCB 95 effects on all spine types (ANOVA: $F_{(3,88)}$, total $F=11.24, p<0.0001$, mushroom $F=9.282, p<0.0001$, stubby $F=8.253, p<0.0001$, filopodia $F=0.1983, p=0.8973$, Tukey's post hoc; Fig. $4 B)$. Treatment with 
PCB 95, anti-miR132, or a combination of both did not change the juxtaposition of synapsin-1 immunoreactivity with $\mathrm{RFP}^{+}$ dendritic spines (data not shown). Expression of anti-miR132 also prevented PCB 95induced increases in mEPSC frequency but did not change mEPSC decay time (ANOVA: $F_{(3,49)}$, Freq $F=17.84, p<$ 0.0001 , DT $F=1.301, p=0.285$, Tukey's post hoc; Fig. 4C,E). There was a slight difference in amplitude between the control PCBtreated group and the anti-miR132-treated group with no PCB exposure (ANOVA: $F_{(3,49)}$, Amp $\left.F=3.195, p=0.031\right)$, but in the same test all other groups were not statistically different from each other, including control versus PCB treatment and anti-miR132 alone versus anti-miR132 with PCB treatment and PCB treatment versus anti-miR132 with PCB treatment (Fig. 4D).

p250GAP is a GTPase activating protein that inhibits the downstream signaling of Rho-family GTPases, and it is a known target of miR132 translational silencing (Nakamura et al., 2002; Okabe et al., 2003; Zhao et al., 2003; Wayman et al., 2008). Active p250GAP inhibits dendritic outgrowth and synaptogenesis, whereas knockdown using shRNA constructs has the opposite effect (Wayman et al., 2008; Impey et al., 2010). Overnight exposure to PCB 95 decreases p250GAP protein in dissociated hippocampal neurons by $\sim 60 \%$ (Student's $t$ test: $p=0.0235$; Fig. $4 F$ ). Expression of cDNA encoding WT p250GAP does not prevent PCB 95 effects on spine density, presumably because PCB 95induced miR132 expression knocks down p250GAP levels (Wayman et al., 2008; Impey et al., 2010) (ANOVA: $F_{(5,137)}$, total $F=20.16, p<0.0001$, mushroom $F=$ $14.74, p<0.0001$, stubby $F=16.12, p<$ 0.0001 , filopodia $F=0.2675, p=0.9303$, Tukey's post hoc; Fig. 4G). However, expression of cDNA encoding MT P250GAP that lacks a functional miR132 regulator element within the $3^{\prime}$ region, and therefore cannot be suppressed by miR132 (Wayman et al., 2008), prevents PCB 95induced increases in dendritic spine density (Fig. 4G). Neither WT p250GAP nor MT p250GAP expression had any significant effect on filopodia density (Fig. $4 G$ ) or changed the percentage of $\mathrm{mRFP}^{+}$ spines in close physical apposition to synapsin-1 immunoreactivity (data not shown).

PCB 95 increases dendritic spine density in hippocampal slice cultures To assess the physiological relevance of results obtained in dissociated hippocampal neurons, we quantified the effects of PCB
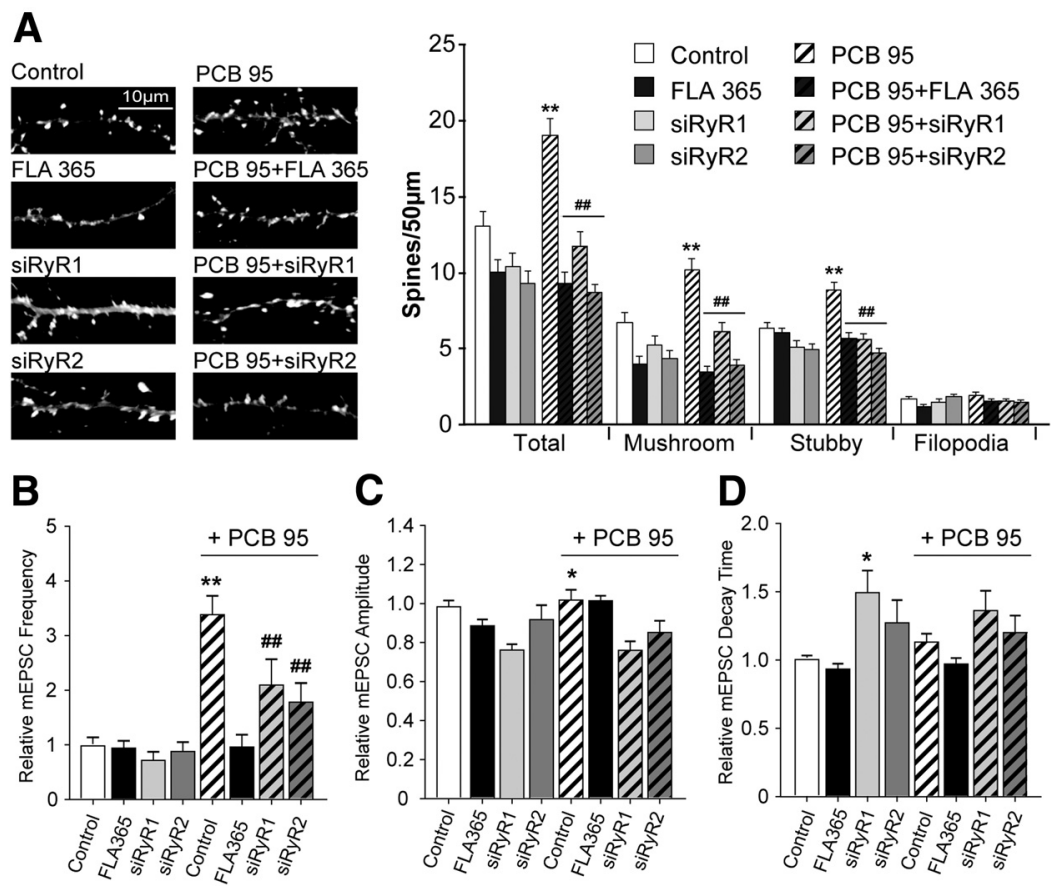

Figure 2. $P C B$ 95-induced synaptogenesis requires RyR activity. DIV6 dissociated hippocampal neurons were transfected with mRFP-tagged $\beta$-actin \pm empty vector, siRyR1 or siRyR2. On DIV7, cells were pretreated for $1 \mathrm{~h}$ with vehicle or FLA365 $(10 \mu \mathrm{m})$ before treatment with PCB 95 (200 nM) until DIV12. $A$, Representative photomicrographs of RFP ${ }^{+}$cells and quantification of dendritic spines and filopodia ( $n=23-24$ neurons). $\boldsymbol{B}-\boldsymbol{D}$, Quantitative analyses of $\mathrm{mEPSCs}(n=28-32$ neurons for control and PCB treatments; $n=11-18$ neurons for FLA365 and siRYR treatments) demonstrating PCB 95 effects on $\mathrm{mEPSC}$ frequency $(\boldsymbol{B})$, amplitude $(\boldsymbol{C})$, and decay time $(\boldsymbol{D})$ presented as the fold change relative to control neurons. *Significantly different from control at $p<0.01$. ${ }^{* *}$ Significantly different from control at $p<0.001$. \#\# Significantly different from PCB 95 alone at $p<0.001$ (one-way ANOVA with post hoc Tukey's analysis).

A
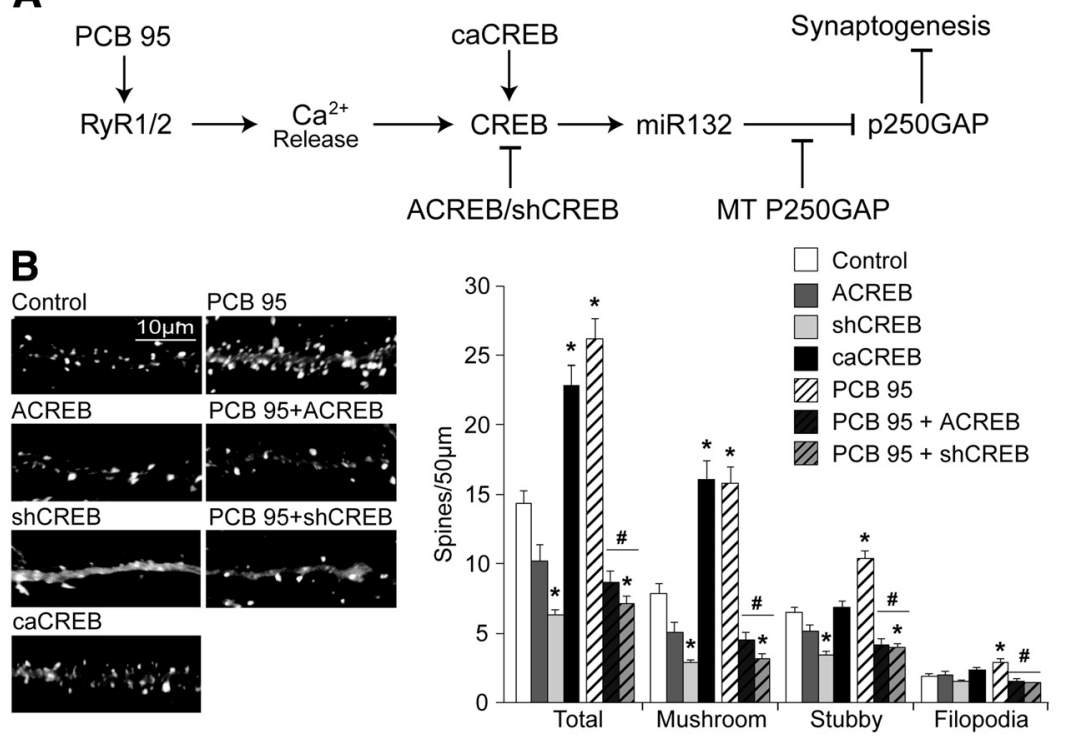

Figure 3. $\quad P C B$ 95-induced spine formation is mediated by CREB activation. $\boldsymbol{A}$, Schematic of CREB-miR132-p250GAP signaling pathway that regulates activity-dependent dendritic spine formation. The CREB-regulated gene miR132 represses translation of p250GAP; p250GAP functions as a negative regulator of spine formation. $\boldsymbol{B}$, DIV6 dissociated hippocampal neurons transfected with mRFP-tagged $\beta$-actin \pm empty vector, shCREB, ACREB (a competitive antagonist of (REB), or constitutively active (REB (caCREB) were treated with vehicle or PCB 95 (200 nm) on DIV7-12. Representative photomicrographs of RFP ${ }^{+}$cells and quantification of dendritic spines and filopodia ( $n=24$ neurons per treatment, except control $n=36$ and caCREB $n=12$ ). *Significantly different from control at $p<0.001$. "Significantly different from PCB 95 alone at $p<0.001$ (one-way ANOVA with post hoc Tukey's analysis). 
A

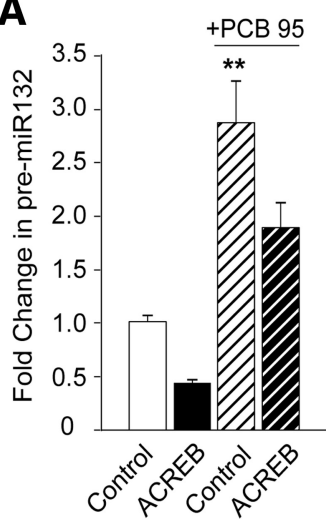

C

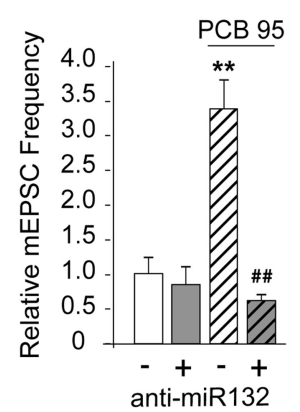

$\mathbf{F}$

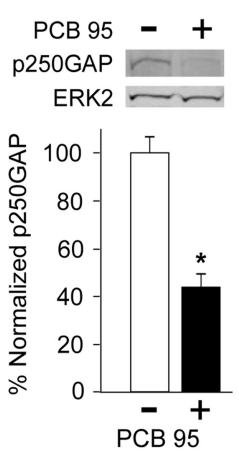

G

Control

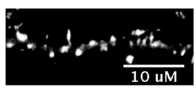

PCB 95

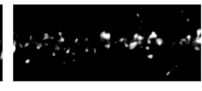

WT p250GAP

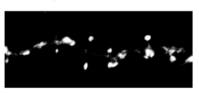

PCB 95+

WT p250GAP

MT p250GAP
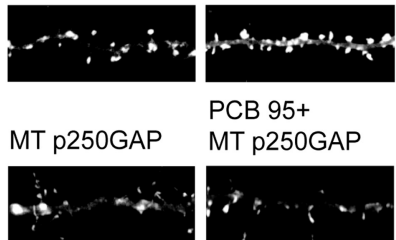

PCB 95+

MT P250GAP

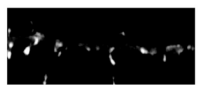

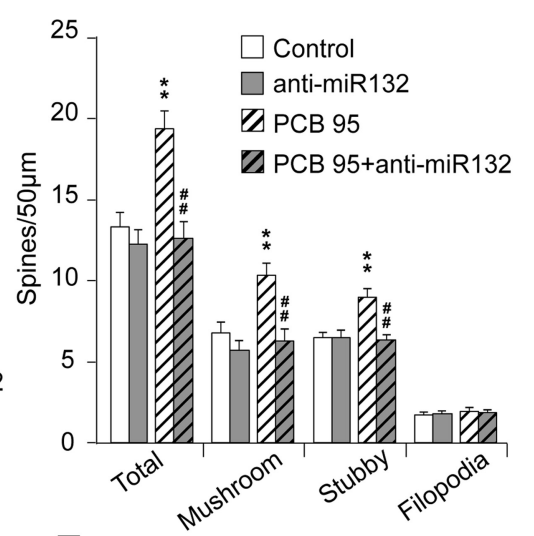

E
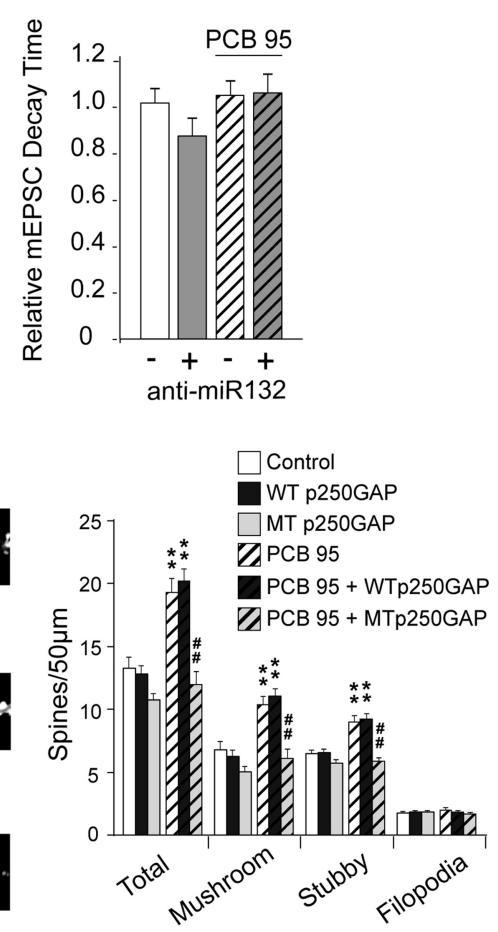

Figure 4. miR132 is required for PCB 95-induced synaptogenesis. $A$, Dissociated hippocampal neurons were electroporated with empty expression vector or ACREB before plating and then cultured until DIV6 when they were treated for $2 \mathrm{~h}$ with vehicle or PCB 95 (200 nm). Pre-miR132 (normalized to HPRT) was determined using qPCR $(n=19-21) \cdot \boldsymbol{B}-\boldsymbol{F}$, DIV6 dissociated hippocampal neurons transfected with mRFP-tagged $\beta$-actin \pm empty vector or anti-miR132 were treated with vehicle or PCB 95 (200 nm) on DIV7-DIV12. $\boldsymbol{B}$, Representative photomicrographs of RFP ${ }^{+}$cells and quantification of dendritic spines and filopodia $(n=21-24$ neurons). $(-\boldsymbol{E}$, Quantitative analyses ( $n=11-16$ neurons) demonstrating PCB 95 effects on mEPSC frequency $(\boldsymbol{C})$, amplitude $(\boldsymbol{D})$, and decay time $(\boldsymbol{E})$ represented as fold change relative to control cultures. $\boldsymbol{F}$, Representative Western blot illustrating p250GAP protein levels in DIV6 dissociated hippocampal neurons treated with vehicle or PCB $95(200 \mathrm{~nm})$ for $24 \mathrm{~h}$. Densitometric values of bands immunoreactive for p250GAP normalized to ERK2 levels within the same sample presented as percentage of control $n=3$ independent samples). G, Dissociated hippocampal neurons transfected on DIV6 with mRFP-tagged $\beta$-actin \pm empty vector, WT p250GAP, or MT p250GAP were treated with vehicle or PCB 95 (200 nM) on DIV7-12. Representative photomicrographs of RFP ${ }^{+}$ cells and quantification of dendritic spines and filopodia ( $n=23-24$ neurons). ${ }^{*} p<0.05$, significantly different from control. ${ }^{* *} p<0.001$, significantly different from control. ${ }^{\# \#} p<0.001$, significantly different from PCB 95 alone (one-way ANOVA with post hoc Tukey's analysis).

95 on spine density in organotypic hippocampal slice cultures. Exposure to PCB 95 at $200 \mathrm{~nm}$ causes a 25\% increase in total dendritic spine density in CA1 pyramidal neurons, which reflects significant increases in both mushroom and stubby spine density (Fig. 5). Consistent with observations in dissociated hippocampal cell cultures, PCB 95 did not change filopodia density in CA1 pyramidal neurons in slice cultures (Fig. 5).

Expression of siRYR1 or siRYR2 inhibits the effects of PCB 95 on spine density in hippocampal slice cultures (ANOVA: $F_{(5,286)}$, total $F=12.94, p<0.0001$, mushroom $F=12.39, p<0.0001$, stubby $F=$ 6.879, $p<0.0001$, filopodia $F=2.241$, $p=0.0504$, Tukey's post hoc; Fig. $5 A$ ). Expression of anti-miR132 also significantly decreases spine density in both PCBtreated slice cultures and control slices (ANOVA: $F_{(3,188)}$, total $F=27.12, p<$ 0.0001 , mushroom $F=18.38, p<0.0001$, stubby $F=20.48, p<0.0001$, filopodia $F=6.793, p=0.0002$, Tukey's post hoc; Fig. 5B). PCB 95-induced formation of dendritic spines was also inhibited by expression of MT p250GAP (ANOVA: $F_{(3,211)}$, total $F=11.43, p<0.0001$, mushroom $F=6.487, p=0.0003$, stubby $F=$ 14.10, $p<0.0001$, filopodia $F=2.986$, $p=0.0322$, Tukey's post hoc; Fig. 5C). Across all conditions, filopodia densities were only decreased with transfection of anti-miR132 in conjunction with PCB 95 treatment (Fig. 5A-C).

\section{Discussion}

Despite an extensive literature documenting that PCBs interfere with normal neurodevelopment in humans and experimental animal models (Seegal, 1996; Schantz et al., 2003; Carpenter, 2006; Korrick and Sagiv, 2008; Winneke, 2011), only recently have adverse outcome pathways of PCB developmental neurotoxicity been described. We recently reported that PCB 95 stimulates CaMKICREB-Wnt2 signaling via RyR-dependent mechanisms to enhance dendritic growth in hippocampal neurons (Wayman et al., 2012a, b). Here, we extend these observations to demonstrate that PCB 95 also increases the density of synapses along dendrites, as indicated by morphological (spine formation), immunocytochemical (juxtaposition of $\mathrm{mRFP}^{+}$spine heads with presynaptic and postsynaptic markers), and electrophysiological (mEPSC frequency) indicators. This is consistent with recent proteomic studies showing that NDL PCBs increase expression of synaptic proteins in rat cerebellar neurons (Brunelli et al., 2012).

The observation that PCB 95 causes a $50 \%$ increase in spine density but a threefold increase in mEPSC frequency raises the question of whether the increase in mEPSC frequency can be accounted for exclusively by an increase in synapse number. Although experimental evidence clearly shows a positive correlation between spine density and mEPSC density (Murase et al., 2002), there are no experimental data to indicate this is a 1:1 correlation. RyRs are expressed not only in postsynaptic dendrites but also in presynaptic axons (Hertle and 
A
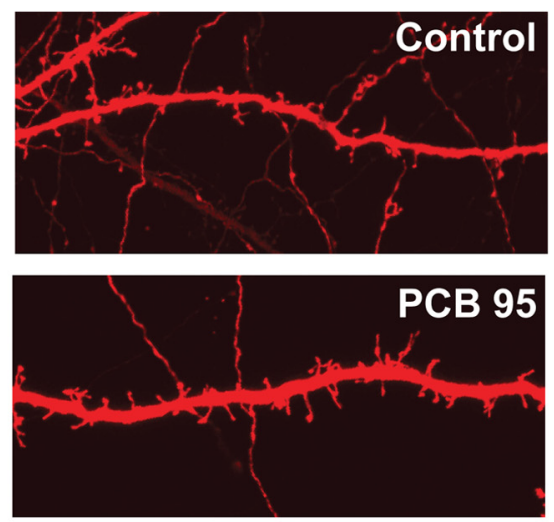

B

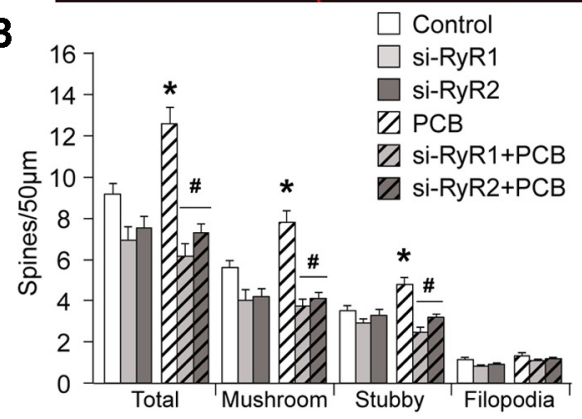

C

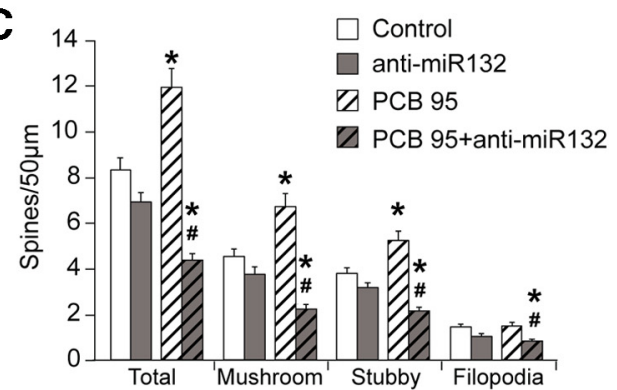

D

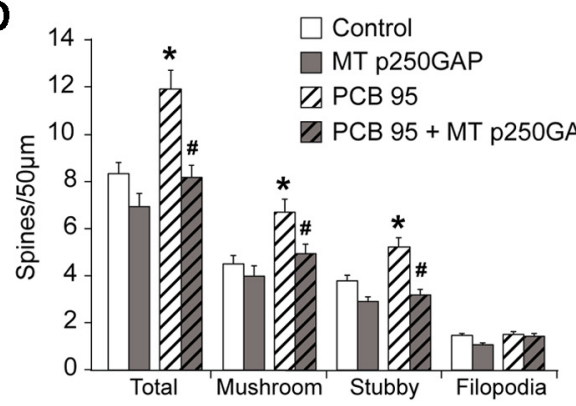

Figure 5. $P C B$ 95 induces spine formation in organotypic hippocampal slice cultures. Organotypic hippocampal slice cultures were transfected on DIV2 with TFP \pm empty vector, siRyR1, siRyR2, anti-miR132, or MT p250GAP. On DIV4, slice cultures were treated with vehicle or PCB $95(200 \mathrm{~nm})$ for $48 \mathrm{~h}$. A, Representative photomicrographs of TFP ${ }^{+}$CA1 pyramidal neurons exposed to vehicle (control) or treated with PCB 95. B-D, Quantification of dendritic spines and filopodia $(n=34-60)$. ${ }^{*}$ Significantly different from control at $p<0.01$. "Significantly different from PCB 95 alone at $p<0.01$ (one-way ANOVA with post hoc Tukey's analysis).

Yeckel, 2007); therefore, it is possible that PCB 95 works not only to increase spine formation but also to enhance presynaptic release of neurotransmitter. This is consistent with a report that RyR-dependent $\mathrm{Ca}^{2+}$ release from presynaptic internal stores is required for ethanol to increase spontaneous $\gamma$-aminobutyric acid release onto cerebellum Purkinje neurons (Kelm et al., 2007).

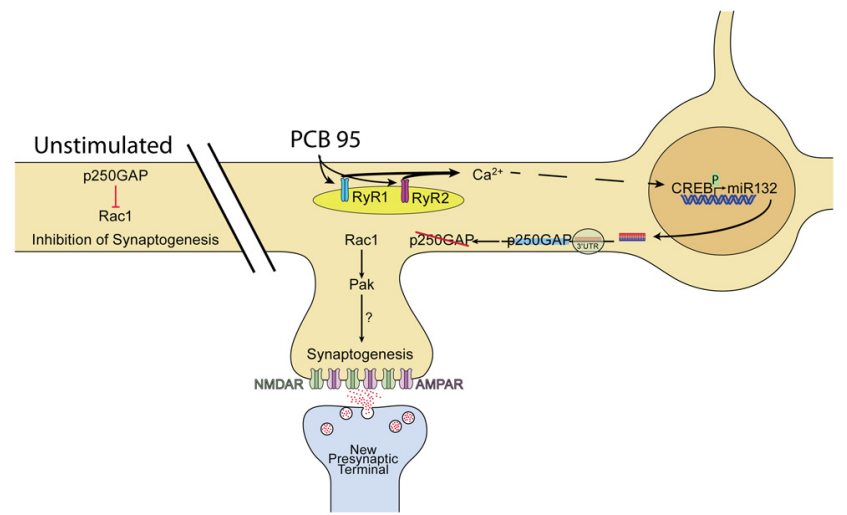

Figure 6. Model of PCB 95-induced synaptogenesis. Under basal conditions, p250GAP suppresses Rac1 activation to repress synaptogenesis. PCB 95 exposure sensitizes RyR1 and RyR2 to increase release of internal $\mathrm{Ca}^{2+}$ stores. Increased cytoplasmic $\mathrm{Ca}^{2+}$ triggers phosphorylation of CREB, stimulating CREB-dependent transcription. CREB activation increases transcription of miR132, a transcriptional repressor that suppresses p250GAP translation. The decreased translation of p250GAP effectively releases inhibition on Rac1 activity to increase synaptogenesis.

Using multiple experimental approaches, including qPCR analyses of miR132 expression and Western blot analyses of p250GAP together with gain-of-function and loss-of-function studies, we established crucial roles for RyR1, RyR2, CREB, miR132, and p250GAP in mediating PCB 95-induced synaptogenesis. Our data support a model (Fig. 6) in which NDL PCBs potentiate RyR activity to activate CREB, which then upregulates miR132, a translational repressor that suppresses p250GAP expression (Wayman et al., 2008). Because p250GAP inhibits Rac1 activity (Moon et al., 2003; Nakazawa et al., 2003; Taniguchi et al., 2003; Zhao et al., 2003; Nasu-Nishimura et al., 2006), the decreased translation of p250GAP effectively releases inhibition on Rac1, resulting in increased synaptogenesis. CREB-miR132p250GAP signaling also mediates activity-dependent synaptogenesis in cultured hippocampal neurons (Impey et al., 2010), suggesting that NDL PCBs interfere with neurodevelopment by mimicking and/or enhancing the effects of neuronal activity, a critical cue in refining patterns of synaptic connectivity in the developing brain (Katz and Shatz, 1996; Yuste and Bonhoeffer, 2001).

Previous studies have implicated RyR activity in synaptogenesis. Local release of $\mathrm{Ca}^{2+}$ from intracellular stores increases the size of dendritic spines (Korkotian and Segal, 1999), and inhibitory concentrations of ryanodine block BDNF-enhanced spine formation in primary hippocampal neurons (Adasme et al., 2011). Because RyRs are functionally coupled to NMDA receptors (Berridge, 2006; Pessah et al., 2010), our findings suggest that RyRs are required for not only PCB-induced synaptogenesis, but also activity-dependent synaptogenesis, expanding the role for RyRs in neuronal plasticity. Interestingly, RyR1 siRNA and RyR2 siRNA were equally effective in blocking the dendrite promoting activity of PCB 95. The specificity of these siRNA constructs was proved in HEK cells (Wayman et al., 2012b), so we assume this also holds true in cultured hippocampal neurons. Why both RyR isoforms are required remains to be determined, but possibilities include that each isoform may regulate a complementary but distinct profile of downstream effectors necessary for synaptogenesis, or that activation of spatially segregated RyR1 and RyR2 channels creates $\mathrm{Ca}^{2+}$ microdomains whose coincident activation is required for enhancing activity-dependent synapse formation. 
MicroRNAs regulate diverse neurodevelopmental processes, synaptic plasticity in the mature brain, and cognitive function (Kaur et al., 2012). Thus, miRNAs are postulated to be functionally relevant targets in developmental neurotoxicity (Kaur et al., 2012; Tal and Tanguay, 2012). However, our data are the first to link toxicant-induced changes in miRNA to adverse neurodevelopmental outcomes. Specifically, we demonstrate that PCB 95 upregulates miR132 expression in cultured hippocampal neurons via CREB-dependent mechanisms, and this is critical for the effect of PCB 95 on synaptogenesis. miR132 mediates activitydependent spine formation in hippocampal neurons both in vitro (Impey et al., 2010) and in vivo (Hansen et al., 2013) and regulates cognitive behavior in rodent models (Hansen et al., 2010, 2013). Interestingly, in vivo studies indicate that, although miR132 is required for cognitive function, overexpression of miR132 to supraphysiological levels of miR132 compromises cognitive function coincident with significantly increased spine formation (Hansen et al., 2013). Spine density is often positively correlated with cognitive capacity; however, histological studies of brains from patients diagnosed with autism spectrum disorders (Hutsler and Zhang, 2010) or fragile X syndrome (Irwin et al., 2001) have revealed significantly increased spine densities in neurons relative to neurotypical controls. These data suggest that hyperconnectivity may be as disruptive to normal cognitive function as hypoconnectivity. Consistent with this hypothesis, developmental exposure to PCB 95 or Aroclor 1254, a commercial mixture of PCBs enriched for NDL PCBs, impairs cognitive behavior in weanling rats at doses that enhance neuronal connectivity in vivo (Schantz et al., 1997; Kenet et al., 2007; Yang et al., 2009).

Interestingly, miR132 represses expression of methyl-CpGbinding protein-2 (MeCP2) (Klein et al., 2007). MeCP2 is a transcriptional repressor, and disruption of its function results in significant dendritic and synaptic dysregulation (Zhou et al., 2006). MeCP2 knock-out animals have significantly perturbed synthesis and release of BDNF, a neurotrophic factor that stimulates dendritic outgrowth and synaptogenesis (Jin et al., 2003; Wang et al., 2006; Rex et al., 2007). Dysfunction of MeCP2 has been implicated in significant cognitive impairment, and both mutations and duplications of the gene have been associated with Rett syndrome and ASDs (LaSalle and Yasui, 2009; Percy, 2011; Cukier et al., 2012). miR132 has also been shown to interact with fragile $\mathrm{X}$ mental retardation protein to regulate synapse formation (Edbauer et al., 2010). More recently, expression of miR132 has been shown to be dysregulated in schizophrenia (Kim et al., 2010; Miller et al., 2012). Collectively, these observations suggest the possibility that NDL PCBs contribute to an increased risk of neurodevelopmental disorders. This possibility is supported by a recent report that PCB 95, but not other PCBs or PBDEs, are significantly higher in postmortem brains of children with a syndromic form of autism, compared with neurotypical controls (Mitchell et al., 2012). The concentrations of PCB 95 we observed to increase spineogenesis in cultured hippocampal neurons correspond to $\sim 6.5 \mathrm{ng} / \mathrm{g}$, which is comparable to the levels of PCB 95 detected in the brains of autistic children (3-15 ng/g) (Mitchell et al., 2012). However, in light of recently published reports documenting widespread exposure of childbearing-aged women living in the United States to PCBs (Thompson and Boekelheide, 2013), even lower levels of exposure to NDL PCBs might adversely influence neuronal connectivity in the developing brain of genetically susceptible individuals, such as those with heritable deficiencies in MeCP2, FRMP, or miR132-dependent signaling.

\section{References}

Adasme T, Haeger P, Paula-Lima AC, Espinoza I, Casas-Alarcon MM, Carrasco MA, Hidalgo C (2011) Involvement of ryanodine receptors in neurotrophin-induced hippocampal synaptic plasticity and spatial memory formation. Proc Natl Acad Sci U S A 108:3029-3034. CrossRef Medline

Arthur JS, Fong AL, Dwyer JM, Davare M, Reese E, Obrietan K, Impey S (2004) Mitogen- and stress-activated protein kinase 1 mediates cAMP response element-binding protein phosphorylation and activation by neurotrophins. J Neurosci 24:4324-4332. CrossRef Medline

Barria A, Malinow R (2002) Subunit-specific NMDA receptor trafficking to synapses. Neuron 35:345-353. CrossRef Medline

Benoist CC, Wright JW, Zhu M, Appleyard SM, Wayman GA, Harding JW (2011) Facilitation of hippocampal synaptogenesis and spatial memory by C-terminal truncated Nle1-angiotensin IV analogs. J Pharmacol Exp Ther 339:35-44. CrossRef Medline

Berridge MJ (2006) Calcium microdomains: organization and function. Cell Calcium 40:405-412. CrossRef Medline

Bourgeron T (2009) A synaptic trek to autism. Curr Opin Neurobiol 19: 231-234. CrossRef Medline

Brewer GJ (1997) Isolation and culture of adult rat hippocampal neurons. J Neurosci Methods 71:143-155. CrossRef Medline

Brunelli L, Llansola M, Felipo V, Campagna R, Airoldi L, De Paola M, Fanelli R, Mariani A, Mazzoletti M, Pastorelli R (2012) Insight into the neuroproteomics effects of the food-contaminant non-dioxin like polychlorinated biphenyls. J Proteomics 75:2417-2430. CrossRef Medline

Cardinaux JR, Notis JC, Zhang Q, Vo N, Craig JC, Fass DM, Brennan RG, Goodman RH (2000) Recruitment of CREB binding protein is sufficient for CREB-mediated gene activation. Mol Cell Biol 20:1546-1552. CrossRef Medline

Carpenter DO (2006) Polychlorinated biphenyls (PCBs): routes of exposure and effects on human health. Rev Environ Health 21:1-23. CrossRef Medline

Chiesi M, Schwaller R, Calviello G (1988) Inhibition of rapid Ca-release from isolated skeletal and cardiac sarcoplasmic reticulum (SR) membranes. Biochem Biophys Res Commun 154:1-8. CrossRef Medline

Cline HT (2001) Dendritic arbor development and synaptogenesis. Curr Opin Neurobiol 11:118-126. CrossRef Medline

Cukier HN, Lee JM, Ma D, Young JI, Mayo V, Butler BL, Ramsook SS, Rantus JA, Abrams AJ, Whitehead PL, Wright HH, Abramson RK, Haines JL, Cuccaro ML, Pericak-Vance MA, Gilbert JR (2012) The expanding role of MBD genes in autism: identification of a MECP2 duplication and novel alterations in MBD5, MBD6, and SETDB1. Autism Res 5:385-397. CrossRef Medline

DeCaprio AP, Johnson GW, Tarbell AM, Carpenter DO, Chiarenzelli JR, Morse GS, Santiago-Rivera AL, Schymura MJ (2005) Polychlorinated biphenyl (PCB) exposure assessment by multivariate statistical analysis of serum congener profiles in an adult Native American population. Environ Res 98:284-302. CrossRef Medline

Edbauer D, Neilson JR, Foster KA, Wang CF, Seeburg DP, Batterton MN, Tada T, Dolan BM, Sharp PA, Sheng M (2010) Regulation of synaptic structure and function by FMRP-associated microRNAs miR-125b and miR-132. Neuron 65:373-384. CrossRef Medline

Fukuda T, Itoh M, Ichikawa T, Washiyama K, Goto Y (2005) Delayed maturation of neuronal architecture and synaptogenesis in cerebral cortex of Mecp2-deficient mice. J Neuropathol Exp Neurol 64:537-544. Medline

Garey L (2010) When cortical development goes wrong: schizophrenia as a neurodevelopmental disease of microcircuits. J Anat 217:324-333. CrossRef Medline

Hansen KF, Sakamoto K, Wayman GA, Impey S, Obrietan K (2010) Transgenic miR132 alters neuronal spine density and impairs novel object recognition memory. PLoS One 5:e15497. CrossRef Medline

Hansen KF, Karelina K, Sakamoto K, Wayman GA, Impey S, Obrietan K (2013) miRNA-132: a dynamic regulator of cognitive capacity. Brain Struct Funct 218:817-831. CrossRef Medline

Harris KM, Jensen FE, Tsao B (1992) Three-dimensional structure of dendritic spines and synapses in rat hippocampus (CA1) at postnatal day 15 and adult ages: implications for the maturation of synaptic physiology and long-term potentiation. J Neurosci 12:2685-2705. Medline

Hertle DN, Yeckel MF (2007) Distribution of inositol-1,4,5-trisphosphate receptor isotypes and ryanodine receptor isotypes during maturation of the rat hippocampus. Neuroscience 150:625-638. CrossRef Medline 
Hutsler JJ, Zhang H (2010) Increased dendritic spine densities on cortical projection neurons in autism spectrum disorders. Brain Res 1309:83-94. CrossRef Medline

Hwang HM, Green PG, Young TM (2006) Tidal salt marsh sediment in California, USA: 1. Occurrence and sources of organic contaminants. Chemosphere 64:1383-1392. CrossRef Medline

Impey S, Davare M, Lesiak A, Fortin D, Ando H, Varlamova O, Obrietan K, Soderling TR, Goodman RH, Wayman GA (2010) An activity-induced microRNA controls dendritic spine formation by regulating Rac1-PAK signaling. Mol Cell Neurosci 43:146-156. CrossRef Medline

Irwin SA, Patel B, Idupulapati M, Harris JB, Crisostomo RA, Larsen BP, Kooy F, Willems PJ, Cras P, Kozlowski PB, Swain RA, Weiler IJ, Greenough WT (2001) Abnormal dendritic spine characteristics in the temporal and visual cortices of patients with fragile-X syndrome: a quantitative examination. Am J Med Genet 98:161-167. CrossRef Medline

Jin X, Hu H, Mathers PH, Agmon A (2003) Brain-derived neurotrophic factor mediates activity-dependent dendritic growth in nonpyramidal neocortical interneurons in developing organotypic cultures. J Neurosci 23:5662-5673. Medline

Katz LC, Shatz CJ (1996) Synaptic activity and the construction of cortical circuits. Science 274:1133-1138. CrossRef Medline

Kaur P, Armugam A, Jeyaseelan K (2012) MicroRNAs in neurotoxicity. J Toxicol 2012:870150. CrossRef Medline

Kelm MK, Criswell HE, Breese GR (2007) Calcium release from presynaptic internal stores is required for ethanol to increase spontaneous gammaaminobutyric acid release onto cerebellum Purkinje neurons. J Pharmacol Exp Ther 323:356-364. CrossRef Medline

Kenet T, Froemke RC, Schreiner CE, Pessah IN, Merzenich MM (2007) Perinatal exposure to a noncoplanar polychlorinated biphenyl alters tonotopy, receptive fields, and plasticity in rat primary auditory cortex. Proc Natl Acad Sci U S A 104:7646-7651. CrossRef Medline

Kim AH, Reimers M, Maher B, Williamson V, McMichael O, McClay JL, van den Oord EJ, Riley BP, Kendler KS, Vladimirov VI (2010) MicroRNA expression profiling in the prefrontal cortex of individuals affected with schizophrenia and bipolar disorders. Schizophr Res 124:183-191. CrossRef Medline

Klein ME, Lioy DT, Ma L, Impey S, Mandel G, Goodman RH (2007) Homeostatic regulation of $\mathrm{MeCP} 2$ expression by a CREB-induced microRNA. Nat Neurosci 10:1513-1514. CrossRef Medline

Korkotian E, Segal M (1999) Release of calcium from stores alters the morphology of dendritic spines in cultured hippocampal neurons. Proc Natl Acad Sci U S A 96:12068-12072. CrossRef Medline

Korrick SA, Sagiv SK (2008) Polychlorinated biphenyls, organochlorine pesticides and neurodevelopment. Curr Opin Pediatr 20:198-204. CrossRef Medline

Kostyniak PJ, Hansen LG, Widholm JJ, Fitzpatrick RD, Olson JR, Helferich JL, Kim KH, Sable HJ, Seegal RF, Pessah IN, Schantz SL (2005) Formulation and characterization of an experimental $\mathrm{PCB}$ mixture designed to mimic human exposure from contaminated fish. Toxicol Sci 88:400-411. CrossRef Medline

LaSalle JM, Yasui DH (2009) Evolving role of MeCP2 in Rett syndrome and autism. Epigenomics 1:119-130. CrossRef Medline

Lesiak A, Pelz C, Ando H, Zhu M, Davare M, Lambert TJ, Hansen KF, Obrietan K, Appleyard SM, Impey S, Wayman GA (2013) A genome-wide screen of CREB occupancy identifies the RhoA inhibitors Par6C and Rnd3 as regulators of BDNF-induced synaptogenesis. PloS One 8:e64658. CrossRef Medline

Mack WM, Zimányi I, Pessah IN (1992) Discrimination of multiple binding sites for antagonists of the calcium release channel complex of skeletal and cardiac sarcoplasmic reticulum. J Pharmacol Exp Ther 262:1028-1037. Medline

Miller BH, Zeier Z, Xi L, Lanz TA, Deng S, Strathmann J, Willoughby D, Kenny PJ, Elsworth JD, Lawrence MS, Roth RH, Edbauer D, Kleiman RJ, Wahlestedt C (2012) MicroRNA-132 dysregulation in schizophrenia has implications for both neurodevelopment and adult brain function. Proc Natl Acad Sci U S A 109:3125-3130. CrossRef Medline

Mitchell MM, Woods R, Chi LH, Schmidt RJ, Pessah IN, Kostyniak PJ, LaSalle JM (2012) Levels of select PCB and PBDE congeners in human postmortem brain reveal possible environmental involvement in 15q11-q13 duplication autism spectrum disorder. Environ Mol Mutagen 53:589598. CrossRef Medline

Moon SY, Zang H, Zheng Y (2003) Characterization of a brain-specific Rho
GTPase-activating protein, p200RhoGAP. J Biol Chem 278:4151-4159. CrossRef Medline

Murase S, Mosser E, Schuman EM (2002) Depolarization drives $\beta$-catenin into neuronal spines promoting changes in synaptic structure and function. Neuron 35:91-105. CrossRef Medline

Nakamura T, Komiya M, Sone K, Hirose E, Gotoh N, Morii H, Ohta Y, Mori N (2002) Grit, a GTPase-activating protein for the Rho family, regulates neurite extension through association with the TrkA receptor and N-Shc and CrkL/Crk adapter molecules. Mol Cell Biol 22:8721-8734. CrossRef Medline

Nakazawa T, Watabe AM, Tezuka T, Yoshida Y, Yokoyama K, Umemori H, Inoue A, Okabe S, Manabe T, Yamamoto T (2003) p250GAP, a novel brain-enriched GTPase-activating protein for Rho family GTPases, is involved in the $N$-methyl-D-aspartate receptor signaling. Mol Biol Cell 14: 2921-2934. CrossRef Medline

Nasu-Nishimura Y, Hayashi T, Ohishi T, Okabe T, Ohwada S, Hasegawa Y, Senda T, Toyoshima C, Nakamura T, Akiyama T (2006) Role of the Rho GTPase-activating protein RICS in neurite outgrowth. Genes Cells 11: 607-614. CrossRef Medline

Okabe T, Nakamura T, Nishimura YN, Kohu K, Ohwada S, Morishita Y, Akiyama T (2003) RICS, a novel GTPase-activating protein for Cdc42 and Racl, is involved in the $\beta$-catenin-N-cadherin and N-methyl-Daspartate receptor signaling. J Biol Chem 278:9920-9927. CrossRef Medline

Penzes P, Cahill ME, Jones KA, Srivastava DP (2008) Convergent CaMK and RacGEF signals control dendritic structure and function. Trends Cell Biol 18:405-413. CrossRef Medline

Percy AK (2011) Rett syndrome: exploring the autism link. Arch Neurol 68:985-989. CrossRef Medline

Pessah IN, Cherednichenko G, Lein PJ (2010) Minding the calcium store: ryanodine receptor activation as a convergent mechanism of PCB toxicity. Pharmacol Ther 125:260-285. CrossRef Medline

Rex CS, Lin CY, Kramár EA, Chen LY, Gall CM, Lynch G (2007) Brainderived neurotrophic factor promotes long-term potentiation-related cytoskeletal changes in adult hippocampus. J Neurosci 27:3017-3029. CrossRef Medline

Safe SH (1994) Polychlorinated biphenyls (PCBs): environmental impact, biochemical and toxic responses, and implications for risk assessment. Crit Rev Toxicol 24:87-149. CrossRef Medline

Saneyoshi T, Wayman G, Fortin D, Davare M, Hoshi N, Nozaki N, Natsume T, Soderling TR (2008) Activity-dependent synaptogenesis: regulation by a CaM-kinase kinase/CaM-kinase I/betaPIX signaling complex. Neuron 57:94-107. CrossRef Medline

Saneyoshi T, Fortin DA, Soderling TR (2010) Regulation of spine and synapse formation by activity-dependent intracellular signaling pathways. Curr Opin Neurobiol 20:108-115. CrossRef Medline

Santos AR, Duarte CB (2008) Validation of internal control genes for expression studies: effects of the neurotrophin BDNF on hippocampal neurons. J Neurosci Res 86:3684-3692. CrossRef Medline

Schantz SL, Seo BW, Moshtaghian J, Amin S (1997) Developmental exposure to polychlorinated biphenyls or dioxin: do changes in thyroid function mediate effects on spatial learning? Am Zool 37:399-408.

Schantz SL, Widholm JJ, Rice DC (2003) Effects of PCB exposure on neuropsychological function in children. Environ Health Perspect 111:357576. CrossRef Medline

Seegal RF (1996) Epidemiological and laboratory evidence of PCB-induced neurotoxicity. Crit Rev Toxicol 26:709-737. CrossRef Medline

Segal M (2005) Dendritic spines and long-term plasticity. Nat Rev Neurosci 6:277-284. CrossRef Medline

Stewart P, Darvill T, Lonky E, Reihman J, Pagano J, Bush B (1999) Assessment of prenatal exposure to PCBs from maternal consumption of Great Lakes fish: an analysis of PCB pattern and concentration. Environ Res 80:S87-S96. CrossRef Medline

Svitkina T, Lin WH, Webb DJ, Yasuda R, Wayman GA, Van Aelst L, Soderling SH (2010) Regulation of the postsynaptic cytoskeleton: roles in development, plasticity, and disorders. J Neurosci 30:14937-14942. CrossRef Medline

Tal TL, Tanguay RL (2012) Non-coding RNAs: novel targets in neurotoxicity. Neurotoxicology 33:530-544. CrossRef Medline

Taniguchi S, Liu H, Nakazawa T, Yokoyama K, Tezuka T, Yamamoto T (2003) p250GAP, a neural RhoGAP protein, is associated with and phos- 
phorylated by Fyn. Biochem Biophys Res Commun 306:151-155. CrossRef Medline

Thompson MR, Boekelheide K (2013) Multiple environmental chemical exposures to lead, mercury and polychlorinated biphenyls among childbearing-aged women (NHANES 1999-2004): body burden and risk factors. Environ Res 121:23-30. CrossRef Medline

Wang H, Chan SA, Ogier M, Hellard D, Wang Q, Smith C, Katz DM (2006) Dysregulation of brain-derived neurotrophic factor expression and neurosecretory function in Mecp2 null mice. J Neurosci 26:10911-10915. CrossRef Medline

Wayman GA, Impey S, Marks D, Saneyoshi T, Grant WF, Derkach V, Soderling TR (2006) Activity-dependent dendritic arborization mediated by CaM-kinase I activation and enhanced CREB-dependent transcription of Wnt-2. Neuron 50:897-909. CrossRef Medline

Wayman GA, Davare M, Ando H, Fortin D, Varlamova O, Cheng HY, Marks D, Obrietan K, Soderling TR, Goodman RH, Impey S (2008) An activity-regulated microRNA controls dendritic plasticity by downregulating p250GAP. Proc Natl Acad Sci U S A 105:9093-9098. CrossRef Medline

Wayman GA, Bose DD, Yang D, Lesiak A, Bruun D, Impey S, Ledoux V, Pessah IN, Lein PJ (2012a) PCB-95 modulates the calcium-dependent signaling pathway responsible for activity-dependent dendritic growth. Environ Health Perspect 120:1003-1009. CrossRef Medline

Wayman GA, Yang D, Bose DD, Lesiak A, Ledoux V, Bruun D, Pessah IN,
Lein PJ (2012b) PCB-95 promotes dendritic growth via ryanodine receptor-dependent mechanisms. Environ Health Perspect 120:9971002. CrossRef Medline

Winneke G (2011) Developmental aspects of environmental neurotoxicology: lessons from lead and polychlorinated biphenyls. J Neurol Sci 308: 9-15. CrossRef Medline

Yang D, Kim KH, Phimister A, Bachstetter AD, Ward TR, Stackman RW, Mervis RF, Wisniewski AB, Klein SL, Kodavanti PR, Anderson KA, Wayman G, Pessah IN, Lein PJ (2009) Developmental exposure to polychlorinated biphenyls interferes with experience-dependent dendritic plasticity and ryanodine receptor expression in weanling rats. Environ Health Perspect 117:426-435. CrossRef Medline

Yuste R, Bonhoeffer T (2001) Morphological changes in dendritic spines associated with long-term synaptic plasticity. Annu Rev Neurosci 24: 1071-1089. CrossRef Medline

Zhao C, Ma H, Bossy-Wetzel E, Lipton SA, Zhang Z, Feng GS (2003) GCGAP, a Rho family GTPase-activating protein that interacts with signaling adapters Gab1 and Gab2. J Biol Chem 278:34641-34653. CrossRef Medline

Zhou Z, Hong EJ, Cohen S, Zhao WN, Ho HY, Schmidt L, Chen WG, Lin Y, Savner E, Griffith EC, Hu L, Steen JA, Weitz CJ, Greenberg ME (2006) Brain-specific phosphorylation of $\mathrm{MeCP} 2$ regulates activity-dependent Bdnf transcription, dendritic growth, and spine maturation. Neuron 52: 255-269. CrossRef Medline 